\title{
Technological and Human Development of Smart Cities: An Empirical Characterization of EUROCITIES Case Studies
}

\author{
María E. Cortés-Cediel \\ Universidad Complutense de Madrid \\ mcorte04@ucm.es
}

\author{
Iván Cantador \\ Universidad Autónoma de Madrid \\ ivan.cantador@uam.es
}

\author{
Manuel Pedro Rodríguez Bolívar \\ Universidad de Granada \\ $\underline{\text { manuelp@ugr.es }}$
}

\begin{abstract}
Smart Cities are conceived as strategic models to confront the wicked problems that exist in urban contexts. The research literature, however, reflects a lack of consensus on the elements that make a city "smart." While some authors focus on technological aspects, others consider human factors as principal targets of the cities' initiatives. Aiming to shed light on this discrepancy and understand what makes a city smarter, in this paper, we analyze a large number of real case studies implemented in major European Smart Cities. From our analysis, we first characterize and categorize the cities according to theoretical Smart City models proposed in the literature. Based on the cities' characteristics and categories, we then compare them according to external variables, such as their positions in worldwide Smart City rankings, and their administrative contexts.
\end{abstract}

\section{Introduction}

Smart Cities (SCs) are conceived as strategic models to confront the wicked problems that exist in urban contexts [28]. They can be understood as a conceptual spectrum in which urban planners design and implement initiatives aimed to achieve an efficient development and sustainable management of the resources and services in the cities. Labeling a city as "smart" is a complicated matter. As Caragliu et al. pointed out [10], the term Smart City does not have a specific definition and represents a fuzzy concept. Authors like Meijer and Rodríguez Bolívar [25] indicate that the lack of concreteness about such concept has arisen from the attempt to define what a $\mathrm{SC}$ is in different research communities. Hence, several SC conceptualizations have been proposed in distinct areas, such as urban planning, engineering and economics [28]. This means that in practice cities are developing smart solutions under different perspectives, and urban planners are designing and implementing SC strategies taking as reference distinct factors in each case.
Some experts have put the focus on the technological components of smart solutions. For them, a SC cannot be conceived without technological infrastructures that facilitate sustainable development, and represent the way to achieve the best quality of life as possible [30][36]. Other authors, by contrast, argue that what makes a city smart is the human capital, instead of the adoption of technological solutions. An interconnected and productive society is not only capable of promoting a change in institutions, but also improving the quality of life in a creative way [5][24][29].

Aiming to shed light on this discrepancy, and understand what makes a city smarter, in this paper we propose to analyze the nature of smart solutions that have been and are being developed. For such purpose, we conduct an empirical comparison of a set of real initiatives developed in principal SCs.

More specifically, we analyze a large number of case studies reported by the EUROCITIES network ${ }^{1}$ that represent real "smart" initiatives implemented in major European cities. In our analysis, we characterize and categorize these cities according to theoretical SC models proposed in the literature -Nam' and Pardo's [26], and Kummitha' and Crutzen's [22] models- that aim to discern the technological and human developments of SCs.

Then, we compare the cities not only according to the identified characteristics and categories, but also in terms of external variables, such as the cities' positions in worldwide SC rankings, and the administrative regions the cities belong to.

On the one hand, the $\mathrm{SC}$ rankings evaluate and score cities all over the world by means of heterogeneous indicators for diverse aspects - such as technology, human capital, social cohesion, economy, governance, mobility, environment, and urban planning-, and represent a well-established method to measure the development of SCs [16]. Hence, taking the cities' ranking positions into account allows determining which of their

\footnotetext{
${ }^{1}$ http://eurocities.eu
} 
characteristics make them smarter; in particular, we will use two popular rankings to make the assessment of the cities more reliable. On the other hand, based on Public Administration theories, the administrative contexts are related to the preferences of urban planners when designing and implementing SC initiatives. Considering these preferences allows determining whether there are certain patterns of SCs among countries and regions, and whether such patterns could be influencing the effectiveness of the corresponding SC initiatives.

With all the above, in this paper, we state the following 3 research questions:

- RQ1: Which factors, technological or human, make a city "smarter"?

To address this question, we will analyze if top ranked SCs show a significant higher interest in technological or human factors, which will be identified by applying theoretical SC models proposed in the research literature.

- RQ2: How do the theoretical SC models reflect the factors addressed in real initiatives?

To address this question, we will compare the distribution of SC types (i.e., schools of thought) reported in the research literature, and that associated to the analyzed SC initiatives.

- RQ3: Are there SC conceptualizations according to different administrative contexts?

To address this question, we will consider country regions that historically have been characterized by particular administrative systems, and will analyze if there are SC patterns and correlations between the addressed factors and ranking scores of the SCs in such regions.

In addition to providing answers to these research questions, and differently to previous work, this paper contributes by presenting a series of empirical analyses conducted on a large number of real SC initiatives, and by providing all the data collected for analysis as an online available dataset.

\section{Smart City models}

The inadequate management of resources in the cities has increased the appearance of serious urban problems, such as air pollution, mobility difficulties, high unemployment rates, and increase in criminal activities [17]. To mitigate these problems, urban planning strategies for SCs emerged [11] and are increasingly gaining momentum.

A SC is conceived as a way to manage problems in the urban environment and achieve more sustainable urban development [1]. The strategy to develop this vision, however, has been understood and treated in the literature in different ways.

The fact is that the use of ICT in the urban environment meant a paradigm shift in the strategic planning of the cities. Therefore, some authors conceive the concept of SC as a functional area articulated by ICTs, without which not only different resources could be managed, but also services in the city, such as education, health and transport [3][19][36].

On the contrary, for other authors, the concept of $\mathrm{SC}$ is far from being limited to the application of technologies within the city [6][7]. According to Albino et al., (2015), the main potential of a SC resides in the social capital and relationships within the urban environment. This can be observed in the model proposed by Nam and Pardo [26], where, in addition to the technological pillar -referred as Technology (TEC) dimension-, the SCs are structured in two other pillars, namely Institutional (INS) and Human (HUM) dimensions. For Nam and Pardo [26], the TEC dimension promotes aspects related to the application of ICT in the urban context, and the HUM dimension is defined by the human infrastructures that comprise the city. According to the authors, these structures consist of intellectual and social capital, which may be characterized by passing through environments of innovation, competitiveness and creativity [12][15]. Examples of these human infrastructures are those that seek social and labor inclusion, networks between organizations, and volunteering. The INS dimension, on the other hand, covers those factors related to the relationships between different stakeholders in the governance context that occurs in the SCs.

The literature is thus divided by establishing which of the above elements, and to what extent, encourage a city to be "smarter." Based on this idea, Kummitha and Crutzen [22] classify the different trends of the literature on SCs into four schools of thought, considering characteristics described by the different authors reviewed. At first place, the Restrictive school of thought emphasizes that the core element of a SC is ICT, and thus the SCs are characterized by high connectivity and data. A second school of thought is the Reflective school, which recognizes the integration of human elements to enhance the power of ICT. On the opposite side of the spectrum, a third school of thought, the Rationalistic or Pragmatic school, puts the human factors as the central element of a SC, without which ICT would be useless. Finally, according to Kummitha and Crutzen [22], there is another more critical school of thought, the Critical school, which denounces that sometimes city initiatives labeled as 
"smart" are implemented forgetting that the urban space must be managed with the aim of improving the citizens' quality of life.

This discrepancy in the literature has encouraged the appearance of several studies that aim to identify what elements make a city "smart" in an integrated and holistic way. In [18], Gil-García et al. identify aspects that define the SC through a review of the literature. Specifically, they identify the following elements that can configure a SC: public services, city administration and management, institutions, governance, engagement and collaboration, human capital and creativity, knowledge economy and probusiness environment, built environment and city infrastructure, natural environment and ecological sustainability, ICT and other technologies, and data and information. Differently, Giffinger and PichlerMilanović [16] compare characteristics of several medium-sized European cities. As a result of their study, they identify six dimensions of action, namely Smart Economy, Smart Mobility, Smart Environment, Smart Governance, Smart Living, and Smart People.

In practice, cities have followed different strategies with respect to the implementation of their "smart" initiatives, and have gone through distinct stages of development over time, moving from technology company driven, to government driven, and finally to citizen driven SC concepts [13]. In this context, among other issues, our aim is to identify which of the perspectives -TEC or HUM- makes the cities smarter. We will frame our research on some of the above considerations and theoretical models, but empirically will analyze real initiatives implemented in SCs.

\section{Sample selection}

As explained in the preceding sections, in order to analyze the technological and human development of SCs, authors have proposed a number of theoretical models, and, according to such models, have surveyed the research literature to characterize and categorize SC notions proposed in scientific publications [18][22].

Differently to previous work, in this paper we empirically analyze real initiatives implemented in current SCs. More specifically, we analyze case studies reported in the EUROCITIES network ${ }^{2}$ for a large number of European cities.

The EUROCITIES network, founded in 1986, is formed by major European cities, and is aimed to promote the economic, political and social development of the cities. As far of August 2019, it

\footnotetext{
${ }^{2}$ http://www.eurocities.eu/eurocities/case-studies
}

consists of over 140 cities from 39 countries, which comprise 130 million citizens.

Its website provides detailed information about a variety of issues of the member cities, such as news, events, publications, projects and case studies, which are associated to 8 forums, namely cooperation, culture, economy, environment, knowledge society, mobility, social affairs, and urban governance.

With the goal of gathering the contents available in the EUROCITIES network website, we implemented a computer program that automatically downloaded and processed all the website pages. The program then built a structured dataset, which we make public online $^{3}$. Among other issues, the dataset contains a variety of information about 285 case studies (each of them associated to one or more initiatives implemented in one or several cities) of 113 cities from 24 European countries: identifiers, titles, descriptions, URLs, publication dates, forums, and related issues.

Our study is conducted after a manual inspection and annotation of every downloaded initiative. Among other issues, we analyze the initiatives' cities according to their positions in worldwide $\mathrm{SC}$ rankings (Section 4.1). Hence, from the initial set of initiatives, we discarded those that did not appear in the used rankings. For each initiative, we carefully read its description and documentation to manually assign its implementation years, cities and countries, and the SC dimensions -technology (TEC), institutional (INS) and human (HUM) - and factors it addresses (Section 4.2). We discarded those initiatives for which dimensions and factors could not be identified.

We provide all the above information in our public dataset. As a result of the whole process, the dataset comprises 269 initiatives of 72 cities from 24 countries. Table 1 lists these cities and countries.

\section{Research methodology}

Our research study consists of a number of empirical analyses that characterize and compare the initiatives and cities of our sample according to SC dimensions and factors addressed by the initiatives. Additionally, the analyses consider two variables, namely the position/score of each city within worldwide SC rankings, and the administrative context of the cities' countries. In the following subsections, we present and describe in detail such variables.

\subsection{Smart city ranking}

For our first analysis, aimed to identify which dimensions characterize a city to be "smarter" (RQ1),

${ }^{3}$ http://ir.ii.uam.es/egov 
we need a reference ranking of SCs. In the literature, several rankings have been proposed considering different aspects (e.g., human capital, social cohesion, economy, governance, environment, mobility and transport, urban planning, international outreach, and technology), measuring distinct indicators, and not always including all the same cities.

In order to not limit our analysis to one ranking, and aiming to get a ranking score for the largest number of cities in our sample as possible, we inspected several worldwide SC rankings, and finally selected two of them to build a single aggregated ranking.

In particular, we decided to use the 2019 Cities in Motion Index ${ }^{4}$ and the 2018 Innovation Cities Index ${ }^{5}$, which respectively use 96 and 162 indicators to rank and compare 174 and 500 cities all over the world. We selected these rankings because they consider a large number of indicators and cities, and show a Person Correlation Coefficient of 0.784 , which indicates a strong positive correlation between them.

To merge the above rankings $m$ and $i$, we first normalized the positions $p_{c, m} \in[1,174]$ and $p_{c, i} \in[1,500]$ of each city $c$, generating city scores $s_{c, m}, s_{c, i} \in(0,1]$, where $s_{c, m}=\left(174-p_{c, m}+1\right) / 174$ and $s_{c, i}=\left(500-p_{c, i}+1\right) / 500$. Hence, the first city in a ranking obtains a score of 1 , and the last ranked city obtains a score close to 0. Afterwards, the final ranking was formed by sorting the cities in terms of aggregated scores $s_{c}=\left(s_{c, m}+s_{c, i}\right) / 2$. Table 1 shows the cities of our sample and, indicated within parentheses, their positions in the aggregated ranking.

\subsection{Administrative contexts}

In a second analysis, aimed to show whether there exist particular SC conceptualizations according to different administrative contexts (RQ3), we focus on a variable that correspond to the European administrative contexts of the sampled cities.

An administrative context can be understood as the set of idiosyncratic features that define an administrative system [31][14]. According to Rodríguez Bolívar [31], the administrative contexts can influence the way governments implement new initiatives. In this sense, due to historical reasons, the European Union can be divided into regions (sets of countries) with substantial differences according to the way in which issues related to the administrative systems are developed.

Taking into account previous work [21][31][34], we have grouped the cities belonging to the

\footnotetext{
${ }^{4}$ https://citiesinmotion.iese.edu

5 https://www.innovation-cities.com
}

EUROCITIES network into 5 regions, characterized by particular administrative contexts. These regions are Scandinavian, Anglo-Saxon, Germanic, CentralEastern and Southern countries.

Table 1 shows these regions, together with their countries and cities that belong to our research sample. In the table, for each region, we indicate its number of countries and cities, and for each city, we provide within parentheses the position of the city in the SC ranking presented in Section 4.1. We can observe that on average there are 14.4 cities, and that the cities cover the whole spectrum of the ranking, ranging from the $1^{\text {st }}$ (London, UK) to the $475^{\text {th }}$ (Chisinau, Moldova) position in the ranking.

\section{Table 1. European countries and cities of our sample for each region. The numbers within parentheses indicate the cities' positions in the aggregated worldwide SC ranking.}

\begin{tabular}{|c|c|}
\hline \multicolumn{2}{|c|}{ Anglo-Saxon countries and cities - 2, 11 (avg. pos. 117.1) } \\
\hline Ireland & Dublin (32) \\
\hline UK & $\begin{array}{l}\text { London (1), Edinburgh (52), Glasgow (63), Birmingham } \\
\text { (71), Leeds (77), Liverpool (83), Bristol (157), Belfast } \\
\text { (191), Cardiff (229), } \\
\text { Newcastle (332) }\end{array}$ \\
\hline \multicolumn{2}{|c|}{ Central-Eastern countries and cities - 11, 14 (avg. pos. 217.8) } \\
\hline Bulgaria & Sofia (128) \\
\hline Croatia & Zagreb (140) \\
\hline Czech Republic & Brno (357) \\
\hline Estonia & Tallinn (263) \\
\hline Hungary & Budapest (64) \\
\hline Latvia & Riga (104) \\
\hline Lithuania & Vilnius (94) \\
\hline Moldova & Chisinau (475) \\
\hline Poland & $\begin{array}{l}\text { Warsaw (67), Gdansk (267), Krakow (329), } \\
\text { Katowice (330) }\end{array}$ \\
\hline Slovakia & Bratislava (107) \\
\hline Slovenia & Ljubljana (324) \\
\hline \multicolumn{2}{|c|}{ Germanic countries and cities - 2, 16 (avg. pos. 88.1) } \\
\hline Austria & Vienna (9) \\
\hline Germany & $\begin{array}{l}\text { Berlin (7), Munich (21), Hamburg (27), Frankfurt (31), } \\
\text { Dusseldorf (45), Cologne (51), Leipzig (118), } \\
\text { Karlsruhe (156), Dortmund (168), Nuremberg (205) }\end{array}$ \\
\hline Netherlands & $\begin{array}{l}\text { Amsterdam (6), Eindhoven (69), The Hague (146), } \\
\text { Rotterdam (147), Utrecht (204) }\end{array}$ \\
\hline \multicolumn{2}{|c|}{ Scandinavian countries and cities $-3,7$ (avg. pos. 92.6) } \\
\hline Denmark & Copenhagen (14), Oslo (19), Odense (234) \\
\hline Finland & Helsinki (23) \\
\hline Sweden & Stockholm (17), Malmo (166), Gothenburg (175) \\
\hline \multicolumn{2}{|c|}{ Southern countries and cities - 6, 24 (avg. pos. 154.9) } \\
\hline Belgium & Brussels (48), Antwerp (81), \\
\hline France & $\begin{array}{l}\text { Lyon (53), Nice (76), Lille (103), Toulouse (178), Nantes } \\
(217) \text {, Bordeaux (238), Strasbourg (239), Rennes (268), } \\
\text { Grenoble (280) }\end{array}$ \\
\hline Greece & Athens (74), Thessaloniki (269) \\
\hline Italy & Milan (33), Rome (60), Bologna (258) \\
\hline Portugal & Lisbon (49), Porto (282) \\
\hline Spain & $\begin{array}{l}\text { Madrid (22), Barcelona (24), Valencia (75), Málaga (97), } \\
\text { Zaragoza (313), Gijón (380) }\end{array}$ \\
\hline
\end{tabular}




\section{Analysis}

In this section, we present a number of studies aimed to empirically characterize European SCs in terms of technological and human dimensions and factors [26], and schools of thought [22].

\subsection{Dimensions and factors}

We first study which of the dimensions proposed by Nam and Pardo [26] -i.e., technology (TEC), institutional (INS) and human (HUM) dimensionshave been more/less considered in real SC initiatives, and whether they correlate with the "smartness" (i.e., development) level of the cities of such initiatives, according to worldwide SC rankings.

Figure 1 shows the distribution of the analyzed initiatives across their cities' positions in the aggregated ranking (vertical axis) and their SC dimensions (horizontal axis). We note that the horizontal axis ranges from 1 to 400 (for readability purposes). Although the aggregated ranking has 515 cities, only 73 out of them are cities belonging to the EUROCITIES network. As shown in Table 1, London (UK) is the first EUROCITIES city in the ranking and has position 1, whereas Chisinau (Moldova) is the last one, at position 475 . For clarity purpose, we omit the later in the figure. Hence, the worst ranked city is Gijón (Spain) at position 380.

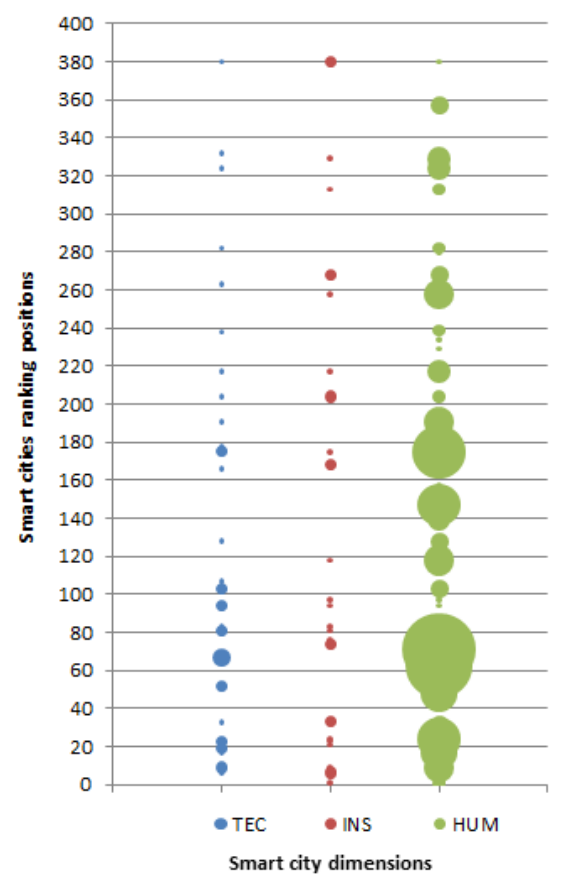

Figure 1. Distribution of the analyzed initiatives across their cities' positions in the aggregated ranking and dimensions.
In the figure, a city is associated to a particular ranking position (i.e., a point in the vertical axis), and may have one, two or three circles if it has EUROCITIES initiatives in one, two or three dimensions, respectively. The size of a circle is proportional to the number of initiatives a city has for the corresponding dimension. For instance, Gothenburg (Sweden), at position 175, has 2, 1 and 9 initiatives for the TEC, INS and HUM dimensions, respectively.

As it can be observed, the TEC initiatives, which are much less than the HUM initiatives, are mainly implemented in the SCs at the top 100 positions of the ranking; specifically, in $52.8 \%$ of the cities, distributed at the top 107 ranking positions. The INS initiatives, which appear in even less cities, by contrast, are distributed uniformly in the ranking. Lastly, the HUM initiatives, which are predominant in the analyzed EUROCITIES case studies, also tend to appear more in cities at the top positions of the ranking; specifically, $60 \%$ of the cities addressing the HUM dimension are distributed in the 70 top positions of the ranking.

Based on these results, we could claim that the smartest cities tend to have some initiatives in the TEC dimension and a relative high number of initiatives in the HUM dimension, which may be complemented with certain INS initiatives. In particular, for the considered EUROCITIES case studies, the 10 top ranked cities $(13.9 \%$ of the cities in our research sample) have $21.9 \%$ of the analyzed initiatives, and represent $45.5 \%$ of the cities with initiatives in all the 3 dimensions.

Hence, SCs not only put people at the core of its initiatives, but also consider both technological and institutional aspects. Next, we will analyze which are the particular factors of the SC dimensions that have been addressed in the EUROCITIES initiatives.

Table 2 shows the dimensions and factors targeted in the EUROCITIES case studies of our research sample, sorted by decreasing number of initiatives in which they have addressed. For the HUM dimension, social inclusion, technology and social learning, and creative and community-based networks, followed by innovation environments, and services for immigrants, family and children aid are the most popular factors. For the TEC dimension, technological and physical infrastructures, and smart computing and digital technologies represent the main goals. Lastly, for the INS dimension, participation in decision making, bottom-up processes complains and suggestions, and social awareness, action and activism, followed by public administration interconnection with other services, and integration and interoperability. 
Table 2. Number of initiatives per Smart City dimension and factor.

\begin{tabular}{|c|c|c|}
\hline \multicolumn{2}{|r|}{ Dimension-Factor } & \#initiatives \\
\hline HUM & Social inclusion & 56 \\
\hline HUM & Technology and learning methods & 31 \\
\hline TEC & Technological/physical infrastructures & 30 \\
\hline HUM & Creative networks & 24 \\
\hline HUM & Cultural actions & 14 \\
\hline INS & Participation in decision making & 11 \\
\hline HUM & Community-based networks and platforms & 8 \\
\hline INS & Bottom-up processes & 7 \\
\hline HUM & Social learning & 6 \\
\hline HUM & Innovation environments & 5 \\
\hline HUM & Services for immigrants & 5 \\
\hline TEC & Smart computing technologies & 4 \\
\hline TEC & Digital technologies & 4 \\
\hline HUM & Family and children aid & 4 \\
\hline TEC & Virtual technologies & 3 \\
\hline INS & Complains and suggestions & 3 \\
\hline INS & Interconnection with other services, NGOs & 3 \\
\hline INS & Social awareness, action and activism & 3 \\
\hline INS & Online public services & 2 \\
\hline INS & Integration and interoperability & 2 \\
\hline INS & Participation in public life & 2 \\
\hline HUM & Use of public spaces & 2 \\
\hline HUM & Creativity & 1 \\
\hline HUM & Volunteering & 1 \\
\hline HUM & Digital education and long-life learning & 1 \\
\hline
\end{tabular}

From these results, we infer that European SCs have put a strong emphasis on issues related to citizens and their participation in public life and decision making, a fact that is evidenced not only in those initiatives targeted to human factors, but also on the majority of the initiatives dealing with institutional factors. This reinforces the idea that technology is not seen as the primary ultimate goal of a SC, but represents a valuable mechanism to support and enhance initiatives that address social issues and problems [5].

Summarizing these results, we provide an answer to RQ1. Top ranked European SCs show a significant interest in implementing initiatives oriented to people for both HUM and INS dimensions and factors. Such initiatives are aimed to improve people's well-being, and increase the citizens' empowerment and participation, and are complemented with TEC initiatives that build and improve the technological and physical infrastructures of the cities.

In addition to identifying which are the main dimensions and factors addressed by the major European SCs, we may ask if they show the same pattern across regions with different administrative contexts. Addressing this question is the goal of our next analysis.
Table 3. Number of initiatives per Smart City dimension grouped by region and country.

\begin{tabular}{|c|c|c|c|}
\hline Region/Country & TEC & INS & HUM \\
\hline Anglo-Saxon countries & 5 & 2 & 46 \\
\hline Ireland & - & - & 3 \\
\hline UK & 5 & 2 & 43 \\
\hline Central-Eastern countries & 11 & 3 & 26 \\
\hline Bulgaria & 1 & - & 3 \\
\hline Croatia & - & - & 4 \\
\hline Czech Republic & - & - & 3 \\
\hline Hungary & 1 & - & - \\
\hline Latvia & 1 & - & 1 \\
\hline Lithuania & 2 & 1 & 1 \\
\hline Moldova & - & - & 1 \\
\hline Poland & 3 & 2 & 9 \\
\hline Slovakia & 1 & - & - \\
\hline Slovenia & 1 & - & 4 \\
\hline Estonia & 1 & - & - \\
\hline Germanic countries & 6 & 11 & 45 \\
\hline Austria & 2 & 1 & 5 \\
\hline Germany & 2 & 6 & 24 \\
\hline Netherlands & 2 & 4 & 16 \\
\hline Scandinavian countries & 8 & 2 & 26 \\
\hline Denmark & 2 & - & 8 \\
\hline Finland & 2 & 1 & 1 \\
\hline Sweden & 4 & 1 & 17 \\
\hline Southern countries & 11 & 15 & 52 \\
\hline Belgium & 2 & 1 & 11 \\
\hline France & 6 & 4 & 15 \\
\hline Greece & - & 2 & 1 \\
\hline Italy & 1 & 3 & 6 \\
\hline Portugal & 1 & - & 6 \\
\hline Spain & 1 & 5 & 13 \\
\hline TOTAL & 41 & 33 & 195 \\
\hline
\end{tabular}

For each of the 3 dimensions, Table 3 shows the number of initiatives by region and country. From the table, we observe that Southern countries, followed by Anglo-Saxon and Germanic countries, are the ones that more SC initiatives have reported in the EUROCITIES network. Central-Eastern and Scandinavian cities, by contrast, are those that give a relative higher emphasis on TEC initiatives -which represent $26.8 \%$ of the total number of TEC initiatives, and $27.5 \%$ of the initiatives in the region. Differently, Southern cities implement $45.5 \%$ of the INS initiatives. As expected from previous analysis results, HUM is the predominant dimension of the initiatives in all regions. In this context, we highlight that Anglo-Saxon and Germanic cities provide the highest relative weight to HUM initiatives.

More specifically, UK arises as the country with the highest number of HUM initiatives, representing $21.9 \%$ of the total number of HUM initiatives in our research sample. Edinburgh $\left(52^{\text {th }}\right.$ position in the ranking), Glasgow $\left(63^{\text {rd }}\right)$ and Birmingham $\left(71^{\text {th }}\right)$ implement $65.2 \%$ of such initiatives. Scandinavian 
countries, headed by Sweden, follow a similar pattern than UK in the sense that both cities barely address the INS dimension. Copenhagen $\left(14^{\text {th }}\right)$ and Oslo $\left(19^{\text {th }}\right)$ in Denmark, Stockholm $\left(17^{\text {th }}\right)$ in Sweden, and Helsinki $\left(23^{\text {th }}\right)$ in Finland, implement $76.9 \%$ of the total number of initiatives in the region. Within the Central-Eastern region, Poland is the country with more initiatives for all dimensions, most of them implemented in Warsaw $\left(25^{\text {th }}\right)$. Lastly, Germanic and Southern cities seem to follow the same pattern. They focus on the HUM dimension, but put a significant effort on the TEC and INS dimensions. In fact, they have $72.7 \%$ of the SCs with initiatives in all the 3 dimensions: Amsterdam $\left(6^{\text {th }}\right)$, Berlin $\left(7^{\text {th }}\right)$, Vienna $\left(9^{\text {th }}\right)$, Munich $\left(21^{\text {st }}\right)$, Antwerp $\left(81^{\text {st }}\right)$, Utrecht $\left(204^{\text {th }}\right)$, Nantes $\left(217^{\text {th }}\right)$ and Gijón $\left(380^{\text {th }}\right)$. Moreover, these regions have the countries with highest numbers of initiatives reported in the EUROCITIES network: Germany and Netherlands in the Germanic region, and Belgium, France and Spain in the Southern region.

In summary, answering RQ3, according to our research sample, we could claim that in the considered European regions -characterized by particular administrative contexts-, there are certain patterns according to the dimensions addressed in their initiatives. Anglo-Saxon and Scandinavian countries put a very strong emphasis on human issues and barely address institutional issues. Germanic and Southern countries also focus on the HUM dimension, but (in less degree) also address the TEC and INS dimensions. By contrast, Central-Eastern countries, which have fewer initiatives, show a balance between TEC and HUM dimensions.

\subsection{Schools of thought}

In a second study, we first characterize the European SCs of our research sample according to Kummitha' and Crutzen's model [22], which consists of city types corresponding to 3 schools of thought, namely restrictive, rationalistic and reflective types ${ }^{6}$. Then, we analyze whether the distribution of the cities among the above schools correspond to that found by Kummitha and Crutzen in their review of the research literature on SCs.

For such purpose, we perform a simple transformation of the cities' representations on the TEC and HUM dimensions, which is based on the definitions of the city types given in [22]. In Table 4, we illustrate the followed transformation method for a set of city examples extracted from our sample, and explain it next.

\footnotetext{
${ }^{6}$ The Critical school is omitted in our study since it does not focus on particular TEC and HUM dimensions.
}

The method consists of two stages. In the first stage, for the TEC dimension, we create a binary 3tuple representation of each city expressing whether the number of TEC initiatives of a city is low, medium or high (columns in the middle of Table 2). In particular, if the city's number of TEC initiatives is lower than its number of HUM initiatives, we establish the city's level of TEC as "low," by setting the TEC-low column value to 1 and setting the TECmedium and TEC-high values to 0 . Otherwise, if the city's number of TEC initiatives is greater than 2 times its number of HUM initiatives, we establish the city's level of TEC as "high," by setting the TEChigh column value to 1 and setting the TEC-low and $T E C$-medium values to 0 . If the two previous conditions are not satisfied, we then establish the city's level of TEC as "medium," by setting the TECmedium column value to 1 and setting the TEC-low and TEC-high values to 0 . This process is conducted analogously for the HUM dimension.

For instance, as shown in Table 4, the city of Amsterdam, with 1 TEC initiative and 2 HUM initiatives, has a relative low number of TEC initiatives and a relative medium number of HUM initiatives, which generate the $(1,0,0)$ and $(0,1,0)$ tuples for the TEC and HUM dimensions, respectively.

Table 4. Examples of city categorizations based on their initiatives dimensions.

\begin{tabular}{|l|cc|ccc|ccc|c|}
\cline { 2 - 10 } \multicolumn{1}{c|}{} & \#initiatives & \multicolumn{3}{|c|}{ TEC } & \multicolumn{3}{c|}{ HUM } & \multirow{2}{*}{$\begin{array}{c}\text { City } \\
\text { type }\end{array}$} \\
\cline { 2 - 10 } & TEC & HUM & low & med. & high & low & med. & high & r \\
\hline London & 0 & 2 & 1 & 0 & 0 & 0 & 0 & 1 & rationalistic \\
\hline Amsterdam & 1 & 2 & 1 & 0 & 0 & 0 & 1 & 0 & reflective \\
\hline Berlin & 1 & 3 & 1 & 0 & 0 & 0 & 0 & 1 & rationalistic \\
\hline Vienna & 2 & 5 & 1 & 0 & 0 & 0 & 0 & 1 & rationalistic \\
\hline Copenhagen & 0 & 5 & 1 & 0 & 0 & 0 & 0 & 1 & rationalistic \\
\hline Stockholm & 1 & 6 & 1 & 0 & 0 & 0 & 0 & 1 & rationalistic \\
\hline Oslo & 2 & 2 & 0 & 1 & 0 & 0 & 1 & 0 & reflective \\
\hline Munich & 1 & 6 & 1 & 0 & 0 & 0 & 0 & 1 & rationalistic \\
\hline Madrid & 0 & 1 & 1 & 0 & 0 & 0 & 0 & 1 & rationalistic \\
\hline Helsinki & 2 & 1 & 0 & 1 & 0 & 1 & 0 & 0 & reflective \\
\hline Barcelona & 0 & 7 & 1 & 0 & 0 & 0 & 0 & 1 & rationalistic \\
\hline Hamburg & 0 & 1 & 1 & 0 & 0 & 0 & 0 & 1 & rationalistic \\
\hline Frankfurt & 0 & 2 & 1 & 0 & 0 & 0 & 0 & 1 & rationalistic \\
\hline Dublin & 0 & 3 & 1 & 0 & 0 & 0 & 0 & 1 & rationalistic \\
\hline Milan & 1 & 0 & 0 & 0 & 1 & 1 & 0 & 0 & restrictive \\
\hline
\end{tabular}

In the second stage, we compare the binary representations of each city to categorize it as restrictive, rationalistic or reflective. Specifically, if the "high" component of a city's TEC tuple is 1, and the "low" component of the city's HUM tuple is 0 , then the city is categorized as restrictive. Analogously, if the "high" component of a city's HUM tuple is 1 , and the "low" component of the city's TEC tuple is 0 , then the city is categorized as rationalistic. In the remaining cases, in which the "medium" component of 
either the TEC or the HUM tuples is 1, the city is categorized as reflective. For instance, as shown in Table 4, the city London, which has associated the $(1,0,0)$ and $(0,0,1)$ tuples for the TEC and HUM dimensions respectively, is categorized as rationalistic, indicating that the city puts a significant more effort in the HUM dimension (2 initiatives) than in the TEC dimension (0 initiatives).

Summarizing the results of the transformation method, Table 5 shows the number of cities of each type -restrictive, reflective and rationalistic- grouped by region and country. From the table, we observe that the majority $(70.8 \%)$ of the cities are categorized as rationalistic, followed by the reflective cities (19.4\%) and the restrictive cities (9.7\%). This distribution is in accordance to that presented by Kummitha and Crutzen in [22] for the SC notions that have been considered in the research literature.

Table 5. Number of cities per Smart City type grouped by region and country.

\begin{tabular}{|l|c|c|c|}
\hline \multicolumn{1}{|c|}{ Region/Country } & \#restrictive & \#reflective & \#rationalistic \\
\hline Anglo-Saxon countries & $\mathbf{1}$ & $\mathbf{1}$ & $\mathbf{9}$ \\
\hline Ireland & 0 & 0 & 1 \\
UK & 1 & 1 & 8 \\
\hline Central-Eastern countries & $\mathbf{3}$ & $\mathbf{3}$ & $\mathbf{8}$ \\
\hline Bulgaria & 0 & 0 & 1 \\
Croatia & 0 & 0 & 1 \\
Czech Republic & 0 & 0 & 1 \\
Hungary & 1 & 0 & 0 \\
Latvia & 0 & 1 & 0 \\
Lithuania & 0 & 1 & 0 \\
Moldova & 0 & 0 & 1 \\
Poland & 0 & 1 & 3 \\
Slovakia & 1 & 0 & 0 \\
Slovenia & 0 & 0 & 1 \\
Estonia & 1 & 0 & 0 \\
\hline Germanic countries & $\mathbf{0}$ & $\mathbf{2}$ & $\mathbf{1 4}$ \\
\hline Austria & 0 & 0 & 1 \\
Germany & 0 & 0 & 10 \\
Netherlands & 0 & 2 & 3 \\
\hline Scandinavian countries & $\mathbf{0}$ & $\mathbf{3}$ & $\mathbf{4}$ \\
\hline Denmark & 0 & 1 & 2 \\
Finland & 0 & 1 & 0 \\
Sweden & 0 & 1 & 2 \\
\hline Southern countries & $\mathbf{3}$ & $\mathbf{5}$ & $\mathbf{1 6}$ \\
\hline Belgium & 0 & 0 & 2 \\
France & 2 & 2 & 5 \\
Greece & 0 & 1 & 1 \\
Italy & 1 & 0 & 2 \\
Portugal & 0 & 1 & 1 \\
Spain & 0 & 1 & 5 \\
\hline & $\mathbf{7}$ & $\mathbf{1 4}$ & $\mathbf{5 1}$ \\
\hline
\end{tabular}

The Central-Eastern and Southern regions include almost all the restrictive cities, characterized by a relatively strong focus on the TEC dimension. The
Southern region concentrates the highest percentage $(35.7 \%)$ of the reflective cities. Lastly, the Germanic and Southern regions have $58.8 \%$ of the rationalistic cities. Almost all the SCs in UK, Germany and Spain are rationalistic.

As a summary of the results of our second study, and addressing RQ2, we have shown that the distribution of restrictive, reflective and rationalistic European SCs derived from our analysis of EUROCITIES case studies corresponds to the distribution reported in [22], which was obtained from a survey of the research literature on SCs, and where rationalist cities focusing on HUM factors are predominant. This applies for all the considered regions, regardless their administrative contexts (RQ3). Certain Central-Eastern and Southern countries also have some restrictive cities, characterized by a strong interest in the TEC dimension.

\section{Conclusions}

Based on the differences in the nature and perspectives on the construction of SCs, this paper presents some insights on how cities, through their implemented initiatives, are understanding the way of becoming smart. To achieve this aim, the paper focuses on the European region in order to make homogeneous comparisons in the same context.

From our analysis, it seems that the best ranked SCs have implemented a higher level of technological solutions and infrastructure than the rest of sample cities. It could mean that SCs should promote the investment in emerging technological infrastructures to reach a wider citizenry and facilitate their involvement in public decisions. In fact, technological infrastructures is the major factor presented in our results, which means that the implementation of emerging technologies is not an option for SCs, but a strategic policy to get higher positions in smart solutions to improve the urban environment.

On another hand, the fact that INS is equally distributed among all sample SCs seems to indicate that the specific outcomes of the SC movement are not only for the introduction of e-government services or accountability and transparency purposes, which were reached by the e-government phenomenon, but the introduction of new and more participative governance models to improve the interaction between city governments and citizenry [31], perhaps with the ultimate aim at increasing the citizens' quality of life [32].

This assertion is confirmed in our results because the participation in decision making is the highest scored factor included into the INS perspective. Therefore, the SC phenomenon is not understood if it 
is not built on participative and collaborative models of governance. It introduces new social contracts [33] between citizens and city governments where the public opinion is settled as the moral referee of the society [8], and as the need of expressing the general will of the citizenry into public policies that drive the forces of the State to achieve the common good [33]. Indeed, if the government cannot serve the interests of people, it should be destroyed and replaced with a better one [33].

In addition, this participation is being focused on social issues as it is shown by the findings of the HUM perspective, and especially in terms of social inclusion, which is the highest scored perspective that SCs are taking into account to become smarter. It makes us to think the power of the humanist perspective of technologies into SCs and how citizens should be involved in public policies for improving this perspective.

Previous comments, nonetheless, do not confirm the rationalist school of thought, which is based on the capabilities of people more than just concentrating around ICTs [22]. By contrast, the findings seem to be in the line of the reflective school of thought where technology appears as an essential element to enhance the capabilities of citizens to innovate and participate in the mainstream and then to solve major problems to create collective common good [4]. In this regard, the introduction of new technologies per se does not have an impact on the smart aspect of the city, but the key aspect here is how this technology allows citizens to participate in decision making processes for improving the social aspects of the community. It implies city governments not only to make a high effort in technological infrastructures, but also in human driven methods for becoming a city smarter [22]. This way, the increased citizen perception of being involved in a virtual community has been demonstrated to have a significant direct association with the use of e-participation platforms [27].

Therefore, the SC phenomenon raises the debate on city governments as responsible for implementing public policies to enhance citizen involvement in public decisions and increase their quality of life. This involvement, nonetheless, could depend on the social context in the urban environment and the technology effect that city governments seeks to achieve on the existing social, political or economic relations, ranging from negligible to disruptive, passing by innovative [9]. It will determine the governance model to be introduced in the SC.

In any case, public policies should be driven both to implement emerging technologies and to foster citizen participation through new technologies. It means to make citizens aware of both the need to be involved in public decision to improve their quality of life and the way their interaction with the city governments is going to be. In other words, technological advances in the urban environment is helping the ancient Greek democracy model into the so-called "Polis" to come back again 2,000 years later, making democracy to have a full sense into the new governance models implemented by SCs. Whenever previous factors be accomplished, recent research has confirmed that the use of technological tools, like social media, are important in supporting the SC program because it increases the interaction between residents and a municipality [35][23].

Findings based on the regions where SCs are located indicate that there are certain patterns on how SCs are conceived and are being implemented in Europe. While the HUM perspective is the most followed in all regions, Anglo-Saxon and Scandinavian cities barely address the INS factors, in comparison with Germanic and Southern cities. Besides, although our sample contained a relatively small number of initiatives per country in the CentralEastern region, we found that its SCs show a relatively high focus on the TEC dimension. In this sense, it has to be noted that these cities, on average, appear at worse positions in the considered worldwide SC ranking (see Table 1). This reinforces the observed trend that top ranked SCs put a very strong emphasis on human factors at both HUM and INS initiatives, and complement it with TEC initiatives to improve the technological and physical infrastructures, but do not consider technology as the primary goal of a SC. Therefore, the SC phenomenon seems to show a persistent socio-technical bifurcation, including "a slew of technological solutions," on one hand, and counselling a socially driven approach [20], on the other, which originates an innovative and disruptive effect in the existing social and political powers of the city governance models.

All the above conclusions are derived from analyses made on a sample that only contains information of initiatives implemented in European SCs. An extension of our study including cities from other continents would be convenient, and is left as a future research work. Despite this limitation, we note that, differently to previous work, we analyze a large number of real case studies, and their cities cover the whole spectrum of worldwide SC rankings, so they could be considered as a representative sample of current SCs all over the world.

Acknowledgements. This work was supported by the Spanish Ministries of Economy, Industry and Competitiveness (TIN2016-80630-P) and Science, Innovation and Universities (CAS18/00035). 


\section{References}

[1] S. Alawadhi, A. Aldama-Nalda, H. Chourabi, J. R. Gil-García, S. Leung, S. Mellouli and S. Walker, "Building understanding of Smart City initiatives," $11^{\text {th }}$ International Conference on Electronic Government, 2012, pp. 40-53.

[2] V. Albino, U. Berardi and R.M. Dangelico, "Smart cities: Definitions, dimensions, performance, and initiatives," Journal of Urban Technology 22(1), 2015, pp. 3-21.

[3] L. Anavitarte and B. Tratz-Ryan, "Market insight: Smart Cities in emerging markets," Gartner, 2010, pp. 39-61.

[4] M. Angelidou. "Smart cities: A conjecture of four forces," Cities 47, 2015, pp. 95-106.

[5] A.V. Anttiroiko, "City-as-a-platform: The rise of participatory innovation platforms in Finnish cities," Sustainability 8(9), 2016, p. 922.

[6] R. Battarra, C. Gargiulo, G. Pappalardo, D.A. Boiano and J.S. Oliva, "Planning in the era of information and communication technologies. Discussing the 'label: Smart' in South-European cities with environmental and socioeconomic challenges," Cities 59, 2016, pp. 1-7.

[7] M. Batty, K.W. Axhausen, F. Giannotti, A. Pozdnoukhov, A. Bazzani, M. Wachowicz and Y. Portugali, "Smart cities of the future," The European Physical Journal Special Topics 214(1), 2012, pp. 481-518.

[8] H. Béjar, "Rousseau: Opinión pública y voluntad general”. Reis 18, 1982, pp. 69-82.

[9] P. Bloom and A. Sancino, Disruptive Democracy: The Clash between Techno-Populism and TechnoDemocracy. USA: SAGE Publications Limited, 2019.

[10] A. Caragliu, C. Del Bo and P. Nijkamp, "Smart cities in Europe," Journal of Urban Technology 18(2), 2011, pp. 65-82.

[11] H. Chourabi, T. Nam, S. Walker, J.R. Gil-García, S. Mellouli, K. Nahon and H.J. Scholl, "Understanding Smart Cities: An integrative framework," 45th Hawaii International Conference on System Sciences, 2012, pp. 2289-2297.

[12] A. Coe, G. Paquet and J. Roy, "E-governance and smart communities: A social learning challenge," Social Science Computer Review 19(1), 2001, pp. 80-93.

[13] B. Cohen (2015, October 8), "The 3 Generations of Smart Cities," retrieved from http://www.fastcoexist.com/ 3047795/the-3-generations-of-smart-cities

[14] O. P. Dwivedi (Ed.), "Administrative culture in a global context," De Sitter Publications, 2005.

[15] R. Florida, "The rise of the creative class" (Vol. 9). Basic books, New York, 2002.

[16] R. Giffinger and N. Pichler-Milanović, "Smart cities: Ranking of European medium-sized cities," Centre of Regional Science, Vienna University of Technology, 2007.

[17] J.R. Gil-García, T.A. Pardo and A. Aldama-Nalda, "Smart cities and smart governments: Using information technologies to address urban challenges," 14th Intl. Conf. on Digital Government Research, 2013, pp. 296-297.

[18] J.R. Gil-García, T.A. Pardo and T. Nam, "What makes a city smart? Identifying core components and proposing an integrative and comprehensive conceptualization," Information Polity 20(1), 2015, pp. 61-87.

[19] C. Harrison, B. Eckman, R. Hamilton, P. Hartswick, J. Kalagnanam, J. Paraszczak and P. Williams, "Foundations for smarter cities," IBM Journal of Research and Development 54(4), 2010, pp. 1-16.
[20] S. Joss, F. Sengers, D. Schraven, F. Caprotti and Y. Dayot, "The smart city as global discourse: Storylines and critical junctures across 27 cities," Journal of Urban Technology 26(1), 2019, pp. 3-34.

[21] W. J. M. Kickert (Ed.). "Public management and administrative reform in Western Europe," Edward Elgar Publishing, 1997.

[22] R. K. R. Kummitha and N. Crutzen, "How Do We Understand Smart Cities? An Evolutionary Perspective," Cities 67, 2017, pp. 43-52.

[23] J.M. López-Quiles and M.P. Rodríguez Bolívar, "Smart technologies for smart governments: A review of technological tools in smart cities," Smart Technologies for Smart Governments. Transparency, Efficiency and Organizational Issues," Springer, 2018, pp. 1-18.

[24] M. Markkula and H. Kune, "Making smart regions smarter: Smart specialization and the role of universities in regional innovation ecosystems," Technology Innovation Management Review 5(10), 2015.

[25] A. Meijer, M.P. Rodríguez Bolívar, "Governing the smart city: A review of the literature on smart urban governance," International Review of Administrative Sciences 82(2), 2016, pp. 392-408.

[26] T. Nam and T.A. Pardo, "Conceptualizing Smart City with dimensions of technology, people, and institutions," 12th International Digital Government Research Conference, 2011, pp. 282-291.

[27] M. Naranjo-Zolotov, T. Oliveira, S. Casteleyn, and Z. Irani, "Continuous usage of e-participation: The role of the sense of virtual community," Government Information Quarterly, 2019 (forthcoming).

[28] G. Nesti, "Defining and assessing the transformational nature of smart city governance: Insights from four European cases," International Review of Administrative Sciences, 2018, 0020852318757063.

[29] A. Oliveira and M. Campolargo, "From smart cities to human smart cities," in 48th Hawaii International Conference on System Sciences, 2015, pp. 2336-2344.

[30] R. Pétercsák, G. Maccani, B. Donellan, M. Helfert and N. Connolly, "Enabling factors for smart cities: A case study," 37th International Conference on Information Systems, 2016.

[31] M.P. Rodríguez Bolívar, "Creative citizenship: The new wave for collaborative environments in Smart Cities," Academia Revista Latinoamericana de Administración 31(1), 2018, pp.277-302.

[32] M.P. Rodríguez Bolívar. "In the search for the 'smart' source of the perception of quality of life in European Smart Cities," 52nd Hawaii International Conference on System Sciences, 2019, pp. 3325-3334.

[33] J. J. Rousseau and G. May, "The social contract: And, the first and second discourses," Yale University Press, 2002. [34] K. Schwab, "The fourth industrial revolution," Currency, 2017.

[35] Suarlan, "Do people support the smart city program? Measuring public support for the smart city program," Master Thesis, Utrecht Universiteit, 2017.

[36] D. Washburn, U. Sindhu, S. Balaouras, R. A. Dines, N.M. Hayes and L.E. Nelson, "Helping CIOs understand 'Smart City' initiatives: Defining the Smart City, its drivers, and the role of the CIO," Forrester Research, 2010. 